Jpn. J. Med. Sci. Biol., 50, 9 - 17, 1997.

\title{
EFFECT OF CYCLOSPORIN A ON TISSUE LIPID PEROXIDATION AND MEMBRANE BOUND PHOSPHATASES IN HYPEROXALURIC RAT AND THE PROTECTION BY VITAMIN E PRETREATMENT
}

\author{
Marimuthu ADHIRAI and Ramasamy SELVAM
}

Department of Biochemistry, Dr. A.L.M. PG Institute of Basic Medical Sciences, University of Madras, Taramani, Madras 600113, India

(Received September 27, 1996. Accepted December 26, 1996)

SUMMARY: The effect of cyclosporin A, a highly effective immunosuppressant, was investigated on hyperoxaluric rats with and without vitamin $\mathrm{E}$ pretreatment. Hyperoxaluria was induced by oral feeding of $3 \%$ ammonium oxalate in water for 3 days. Cyclosprin A (50 mg/kg body wt.) was administered for 3 days. Pretreatment with vitamin E ( $50 \mathrm{mg} / 100 \mathrm{~g}$ body wt., once a week for 3 weeks) was carried out before the administration of cyclosproin $\mathrm{A}$ and ammonium oxalate. Nonenzymatic ascorbate-induced lipid peroxidation was increased to 1.55 -fold in either cyclosporin A-administered or hyperoxaluric rat kidney and liver when compared to control. The lipid peroxidation was further elevated to 1.9-fold when both cyclosporin A and ammonium oxalate were coadministered. The activities of renal and hepatic ATPase, glucose-6-phosphatase as well as the concentrations of thiols were decreased significantly $(\mathrm{p}<0.001)$ when cyclosporin A was administered under hyperoxaluric condition. On pretreatment with vitamin $E$ the cyclosporin A-induced biochemical changes observed in the presence of hyperoxaluria were abolished.

\section{INTRODUCTION}

Cyclosporin A (CsA) is a powerful immunosuppressive drug and has proved to be a potent agent in a wide variety of experimental models of tissue transplantation and in clinical organ transplantation. All modern protocols of immunosuppression include CsA (1). Despite the selective advantage, clinical studies with post-transplant patients have demonstrated that CsA is toxic to kidneys as well as to the liver (2) and the nephrotoxicity and hepatotoxicity consti- 
tute the main dose-limiting factor in the utilization of the drug. The precise toxic mechanism is not clear even though, alterations in mitochondrial functions (3), covalent binding of CsA-metabolites to proteins (4), elevated thromboxane synthesis (5), and lipid peroxidation (LPO)(6) have been reported in the CsAmediated cell damage. Lipid peroxidation reaction has been proposed to be one of the major mechanisms for CsA toxicity and cell injury, based on the partial reversibility by some antiperoxidative agents (7).

CsA enhances renal calcium oxalate deposition in hyperoxaluria by enhancing absorption of oxalate in the intestine (8) as well as retention of oxalate and calcium in the renal cells (9), but the effect of CsA administration on renal and hepatic cell membrane functions in hyperoxaluric condition is not known. This study was aimed, therefore, at investigating the membranal enzymes and LPO status due to CsA administration under hyperoxaluria and the protective effect of vitamin $\mathrm{E}$ (Vit. E) pretreatment under this condition.

\section{MATERIALS AND METHODS}

\section{Experimental design}

Animals: Adult male albino Wistar strain rats weighing 180-200 g were divided into four groups each containing 8-10 rats.

Vitamin E pretreatment: Animals received one ip injection of Vit. E (500 mg $\mathrm{kg}-1$ body wt. w/w) in mineral oil per week for 3 weeks (10).

Drug: Commercially available CsA (Sandimmune; Sandoz Ltd., Basel, Switzerland) was dissolved in olive oil ( $67 \mathrm{mg} \mathrm{ml}-1 \mathrm{w} / \mathrm{v})$. About $0.15 \mathrm{ml}$ was given by daily gavage.

Group 1 received CsA (50 mg kg-1 body wt. w/w) for 3 days; Group 2 received isovolumetric olive oil for 3 days; Group 3 received CsA (50 mg kg-1) for 3 days along with $3 \%$ ammonium oxalate $(\mathrm{AmOx})$ in drinking water; Group 4 received isovolumetric olive oil for 3 days along with $3 \% \mathrm{AmOx}$ in drinking water. The experiments were conducted with and without Vit. E pretreatment.

At the end of the experimental period animals were killed by cervical dislocation and the liver and kidney tissues were quickly dissected into ice-cold saline.

Homogenization: The weighed tissues were homogenized in Tris-HCl buffer $(\mathrm{pH} 7.4,0.01 \mathrm{M})$ with a Potter Elvejhem homogenizer.

Tissue parameters: The thiobarbituric acid-reactive substances (TBARS) formed served as an index of LPO and was measured by the method of 
Devasagayam et al (11). Nonenzymatic LPO in the presence of promoters, ascorbic acid, ferrous sulfate $\left(\mathrm{FeSO}_{4}\right)$ and t-butyl hydroperoxide $(\mathrm{tBH}), 2 \mathrm{mM}$ each was studied.

Microsomal enzyme glucose-6-phosphatase (G6Pase) (12), membrane-bound ATPases (13) and thiols (14) were analyzed.

Statistical analysis: Student's ' $t$ ' test was used for statistical analysis and the ' $p$ ' value was arrived at to assess the statistical significance of the changes observed. Pearson's correlation coefficient ' $r$ ' was arrived at to assess the degree of linear association among the different variables taken two at a time.

\section{RESULTS}

A significant elevation $(p<0.001)$ in the TBARS formation was seen in the presence of promoters of LPO (ascorbate, ferrous sulphate and $t B H$ ). The basal LPO as well as LPO in the presence of promoters was high in both CsA alone- and AmOx alone-treated rat kidney and liver when compared to that of control (Table I). This susceptibility to LPO was further elevated significantly $(p<0.001)$ in the tissues of rats administered with CsA in hyperoxaluric condition.

The Vit. E-pretreated animals of all the experimental groups showed complete protection against tissue peroxidation even in the presence of promoters.

Total thiol, protein and nonprotein thiols were reduced by $20 \%$ in both CsA alone- and AmOx alone-administered rat kidney. Further, decrease of total and protein thiol (30\% each) and nonprotein thiol level (45\%) was observed when CsA was coadministered with $\mathrm{AmOx}$ (9).

The protein thiol concentration of liver was reduced by $30 \%$ to $40 \%$ in CsAas well as AmOx-treated groups (Fig. 1). This concentration was further reduced to $45 \%$ when CsA was given to hyperoxaluric rats. In contrast, nonprotein $\mathrm{SH}$ was not significantly altered. The thiol content was unaffected under the above conditions upon pretreatment with Vit. E. The concentration of thiols negatively correlated with LPO.

The activities of total, $\mathrm{Na}^{+}+\mathrm{K}^{+}-, \mathrm{Mg}^{2+}$ - and $\mathrm{Ca}^{2+}$-dependent ATPases significantly decreased $(\mathrm{p}<0.001)$ in both $\mathrm{AmOx}$ - as well as CsA-treated rat kidney and liver (Table II) and the decrease in their activity was highly significant $(p<0.001)$ in hyperoxaluric rats when coadministered with CsA. ATPase showed negative correlation with LPO. Positive correlation was observed with protein 


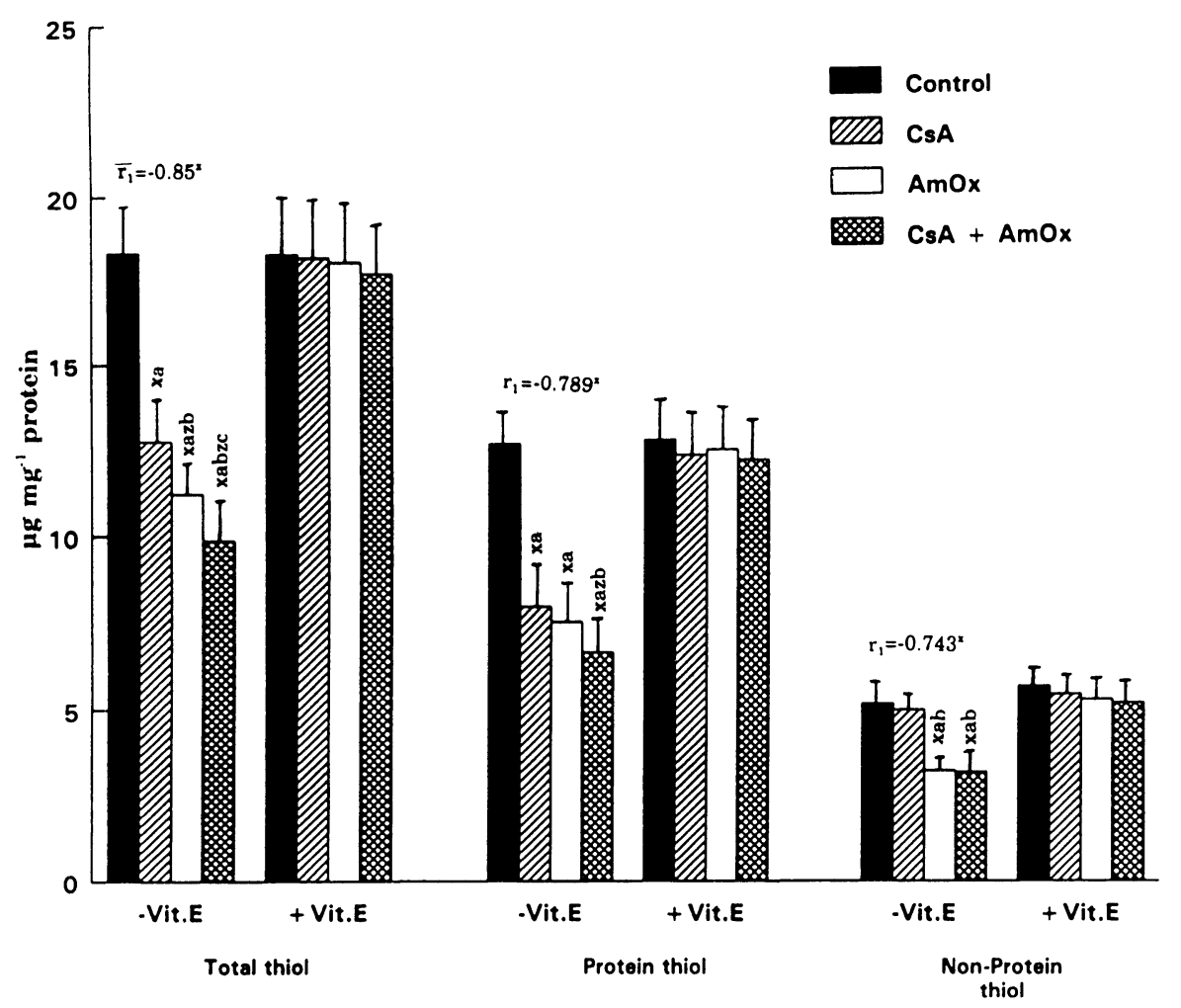

Fig. 1. Effect of CsA administration on the levels of thiols in the liver of rats pretreated with and without Vit. E.

(Values are mean +S.D. for eight animals in each group) Values are statistically different compared to a: control; b:CsA; c:AmOx. Values are statistically significant when, $\mathrm{xp}<0.001 ; \mathrm{yp}<0.01 ; \mathrm{zp}<0.05$. Correlation coefficient $r_{1}$ Vs LPO. -Vit E : Vitamin-E untreated; +Vit. E : Vitamin E-pretreated.

thiol. The above changes were not observed in the Vit. E-pretreated rats on challenging with $\mathrm{CsA}$ and $\mathrm{AmOx}$.

The activity of microsomal enzyme G6Pase was reduced to $45-52 \%$ in both CsA alone- or AmOx-administered rat liver and kidney when compared to that of control. The reduction in enzyme activity was more pronounced (55-63\%) when $\mathrm{CsA}$ and AmOx were co-administered. Pretreatment with Vit. E abolished the above effects. 


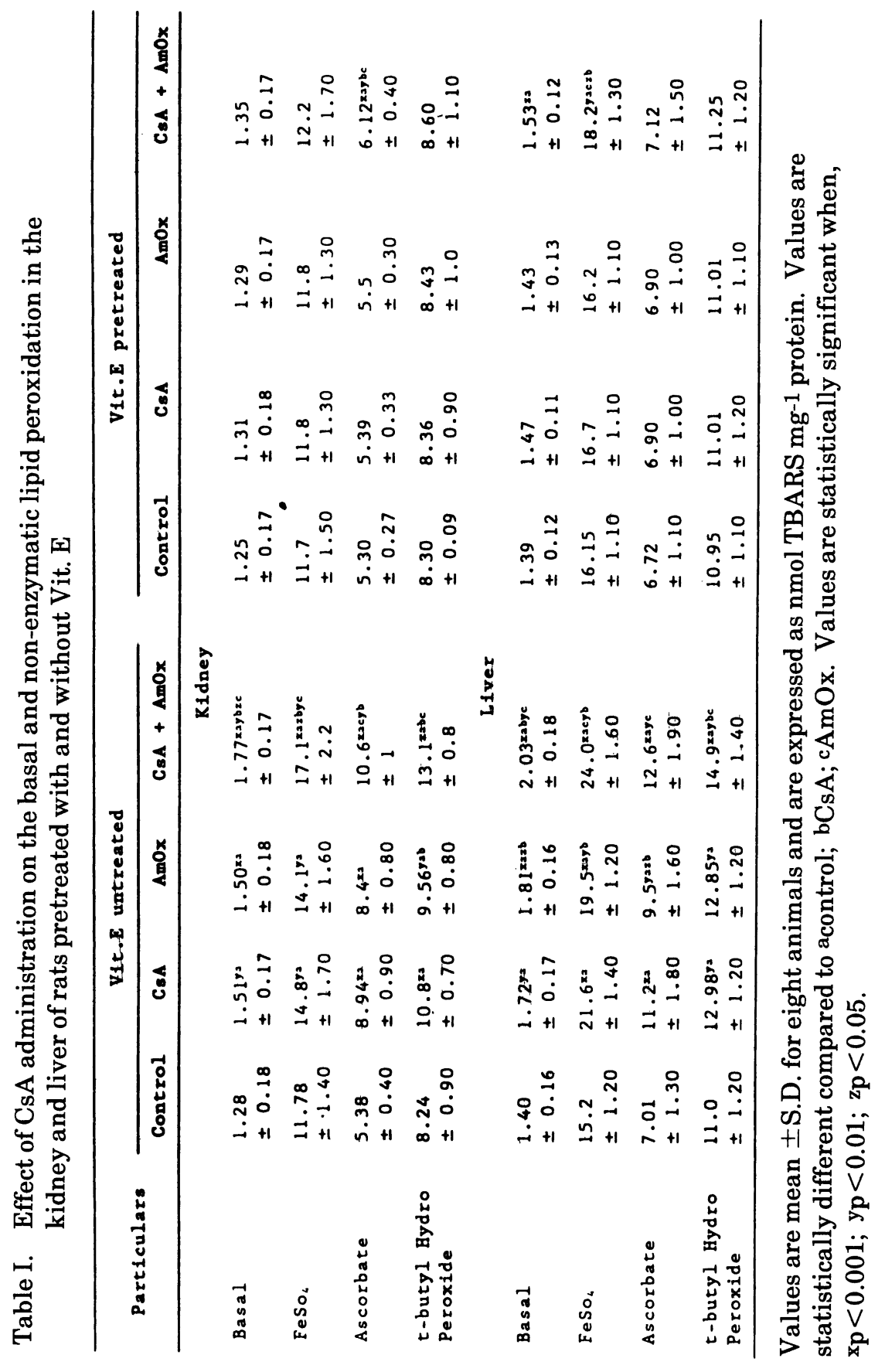




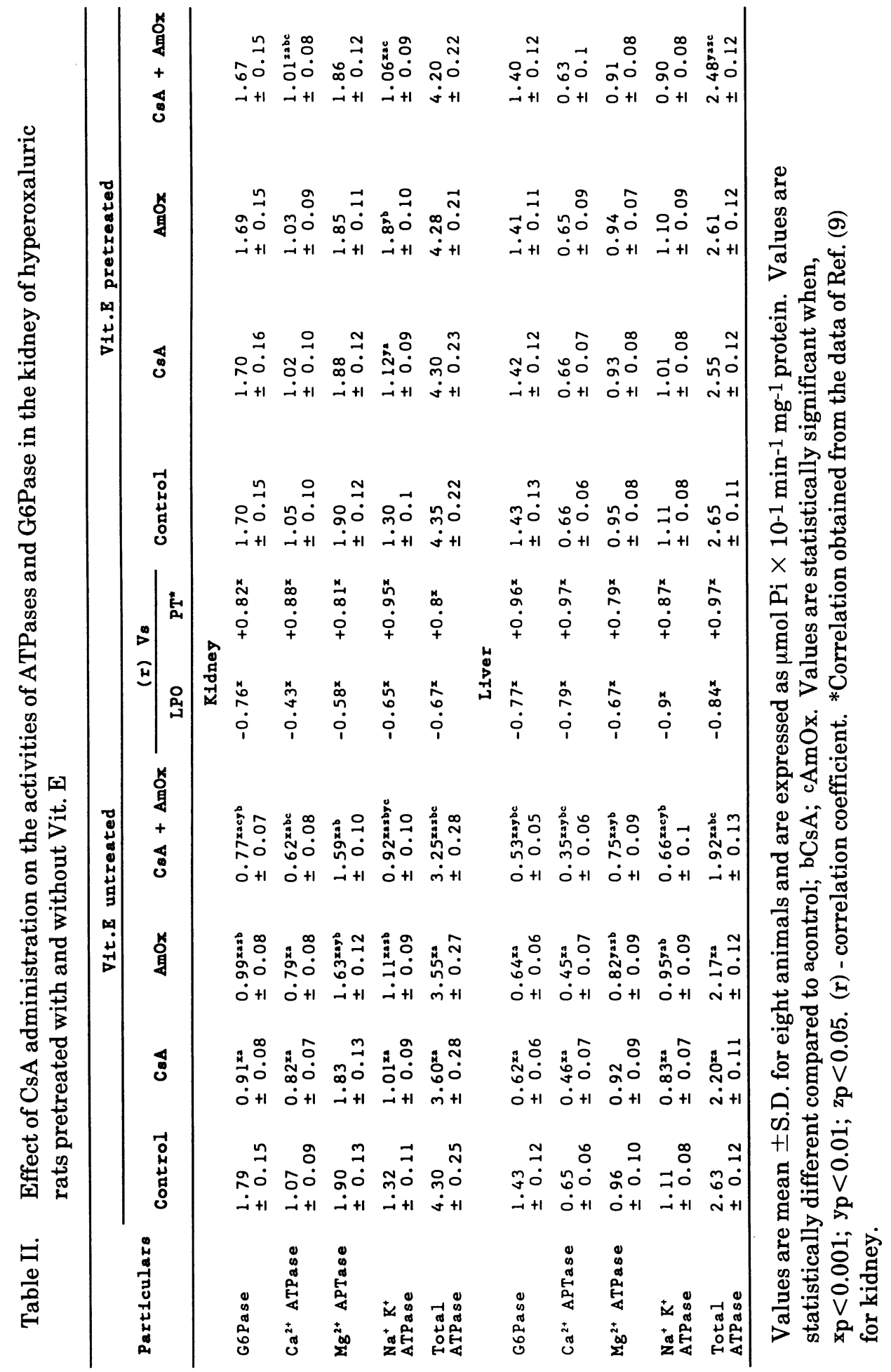




\section{DISCUSSION}

Lipid peroxidation reaction, a type of oxidative degeneration of polyunsaturated fatty acids, has been linked with altered membrane structure and enzyme inactivation (15). The highly significant elevation in nonenzymatic LPO reactions observed in hyperoxaluric rats when administered with CsA suggests the enhanced susceptibility of the membranes. Further oxalate itself is known to induce membrane damage and cell injury as well as LPO $(16,17)$. Since Vit. Epretreatment normalizes the LPO reaction, it suggests the involvement of the radicals in the CsA- as well as AmOx- treated rats. CsA has been shown to enhance in vitro as well as in vivo tissue LPO $(7,18)$.

The decreased activities of membrane-bound enzymes, G6Pase and ATPase also support the fact that the severe damage has been effected by CsA treatment in hyperoxaluria. The decrease in the membrane-bound enzyme activities are found to be associated with the loss of protein thiol content.

ATPases are lipid dependent as well as SH-dependent membrane-bound enzymes and alterations in membrane lipid can lead to changes in membrane fluidity. Further enhanced susceptibility to LPO of membrane can lead to loss of protein thiol, thereby change in membrane functions. The marked loss in G6Pase, total, $\mathrm{Mg}^{2+}+_{-}, \mathrm{Ca}^{2+-}$, and $\mathrm{Na}^{+} \mathrm{K}^{+}-$ATPase activities registered in CsA-treated urolithic rats may be due to loss of protein-SH because of increased lipid peroxidative damage. This is supported by the positive correlation betweeen ATPase and protein thiol activities. The depletion of thiol content may be associated with low concentration of nonprotein thiol as observed here and antioxidants such as ascorbic acid, Vit. E and GSH as well as low activities of GPx as reported earlier (9).

Vitamin E pretreatment protects the membrane-bound enzymes from inactivation by restoration of antioxidants (19) and thereby arresting free radicalinduced damage. Depletion of total thiol has been observed under oxidative stress (20) as well as by administration of drugs (21). G6Pase is known to be inhibited by LPO (22). Decreased levels of total thiols as well as protein thiol have been reported in the urolithic rat liver and kidney when fed with vitamin $\mathrm{B}_{6}$ deficient diet or sodium glycolate-supplemented diet $(23,24)$. Feeding SH-generating substance like methionine (25) or free radical scavengers like Vit. E (19) along with urolithic diet restores the cellular thiol content and the membranal functions. 
In conclusion, CsA induces LPO and membrane biochemical changes, and these changes were well pronounced under hyperoxaluric conditions. Vit. Epretreatment protects the cells from $\mathrm{CsA}$ as well as as oxalate-induced damage.

\section{ACKNOWLEDGMENTS}

One of the authors Marimuthu Adhirai is grateful to the Council of Scientific and Industrial Research, New Delhi, for providing the financial assistance.

\section{REFERENCES}

1. Morris, P. J. (1994): Cyclosporin. P. 179-201. In P. J. Morris (ed.), Kidney Transplantation. W. B. Saunders Co., Pennsylvania.

2. Myers, M. S., Ross, J., Newton, L., luetscher, J. and Perrioth, M. (1984): Cyclosporin associated chronic nephropathy. N. Eng. J. Med., 311, 699-705.

3. Michel, D. and Richard, B. (1991): Cyclosporin inhibits phosphate transport and stimualtes alkaline phosphatase activity in renal BBMV. Am. J. Physiol., 260 (Renal Fluid Electrolyt Physiol., 29), F518-F524.

4. Nakissa, S. and Paul, E. T. (1994): Characterization of rat cytochrome P450 isozymes involved in the covalent binding of cyclosporin A to microsomal proteins. Toxicol. Appl. Pharmacol., 127, 222-232.

5. Grieve, E. M., Hawksworth, G. M., Simpson, J. C. and Whiting, P. H. (1993): The reversal of experimental cyclosporin A nephrotoxicity by thromboxane synthetase inhibition. Biochem. Pharamacol., 45, 1351-1354.

6. Myers, B. D. (1986): Cyclosporin nephrotoxicity. Kidney Int., 30, 964-969.

7. Kumano, K., Yoshida, K., Iwamura, M., Endo, T., Sakai, T., Nakamura, K. and Kuwao, T. (1989): The role of reactive oxygen species in cyclosprin A induced nephrotoxicity in rats. Transplant. Proc., 21 (1, pt. 1), 941-942.

8. Selvam, R. and Adhirai, M. (1997): Vitamin E pretreatment prevents cyclosproin A induced crystal deposition in experimental rat orulithiasis. Nephron, 75, 77-81.

9. Adhirai, M. and Selvam, R. (1996): Protection of cyclosporin A induced biocemical changes by vitamin $\mathrm{E}$ pretreatment in hyperoxaluric rat kidney. J. Nutr. Biochem., in press.

10. Dillard, C. J., Kunert, K. J. and Tappel, A. L. (1982): Effects of Vitamin E, ascorbic acid and mannitol on alloxan induced lipid perioxidation in rats. Arch. Biochem. Biophys., 216, 204-212. 
11. Devasagayam, T. P. A. (1986): Lipid peroxidation in rat uterus. Biochim. Biophys. Acta, 876, 507-514.

12. King, J. (1965): Lactate dehydrogenase. p. 83-93. In N. J. Princeton (ed.), Practical Clinical Enzymology. D. Van Nostrand, Co., London.

13. Evans, D. J., Jr. (1969): Membrane adenosine triphosphatase of E. coli activation by calcium ions and inhibition by monovalent cations. J. Bacteriol., 100, 914-922.

14. Sedlack, J. and Lidsay, R. H. (1968): Estimation of total, protein-bound and non-protein sulphydryl groups in tissues with Ellman's reagent. Anal. Biochem., 25, 192-205.

15. Comporti, M. (1985): Lipid peroxidation and cellular damage in toxic liver injury. Lab. Invest., 53, 599-623.

16. Scheid, C., Kowl, H., Hill, W. A., Luber-Nard, J., Jonassan, J., Honeyman, T., Kennington, L., Kohli, R., Hodapp, J., Ayvazian, P. and Menon, M. (1996): Oxalate toxicity in LLC. PK1 cells, a line of renal epithelial cells. J. Urol., 155, 1112-1116.

17. Selvam, R. and Bijikurien, T. (1987): Induction of lipid peroxidation by oxalate in experimental rat urolithiasis. J. Biol. Sci., 121, 367-373.

18. Barth, S. A., Inselmann, G., Engmann, R. and Heidemann, H. H. (1991): Influences of Ginkgo biloba on cyclosporin A induced lipid peroxidation in human liver microsomes in comparsion to vitamin E, glutathione and $N$ acetylcysteine. Biochem. Pharmacol., 41, 1521-1526.

19. Selvam, R. and Ravichandran, V. (1993): Restoration of tissue antioxidants and prevention of renal stone deposition in vitamin $\mathrm{B}_{6}$ deficient rats fed with vitamin $\mathrm{E}$ or methionine. Indian J. Exp. Biol., 31, 882-887.

20. Meister, A. (1988): Glutathione metabolism and its selective modification. J. Biol. Chem., 263, 17205-17208.

21. Hormann, V. A., Moore, D. R. and Rikans, L. E. (1989): Relative contributions of protein sulfhydryl loss and lipid peroxidation in allyl alcoholinduced cytotoxicity in isolated rat hepatocytes. Toxicol. Appl. Pharmacol., $98,375-384$.

22. Recknagel, R. O. and Ghoshal, A. K. (1965): On the mechanism of carbon tetrachloride toxicity. Coincidence of loss of glucose-6-phosphatase activity with peroxidation of microsomal lipid. Life Sci., 4, 2195-2203.

23. Selvam, R. and Ravichandran, V. (1991): Lipid peroxidation in liver of $\mathrm{B}_{6}$ deficient rats. J. Nutr. Biochem., 2, 245-250.

24. Bijikurien, T. and Selvam, R. (1989): Induction of lipid peroxidation in calcium oxalate stone formation. Ind. J. Exp. Biol., 27, 450-453.

25. Selvam, R. and Bijikurien, T. (1992): Restoration of antioxidants in liver by methionine feeding in experimental rat urolithiasis. Ind. J. Biochem. Biophys., 29, 364-370. 